\title{
Development and Characterization of a Phospholipid Complex for Effective Delivery of Capsaicin
}

\author{
R. MONDAL, Y. BOBDE ${ }^{1}$, B. GHOSH${ }^{1}$ AND T. K. GIRI*
}

NSHM Knowledge Campus, Kolkata Group of Institutions, 124 BL Saha Road, Kolkata-700 053, ${ }^{1}$ Department of Pharmacy, Birla Institute of Technology and Science-Pilani, Hyderabad-500 078, India

\section{Mondal et al.: Phospholipid Complex for Effective Delivery of Capsaicin}

\begin{abstract}
Capsaicin is responsible for the chili's pungent flavour and is used to suppress different types of cancer cells. However, capsaicin causes gastrointestinal irritation and shows poor aqueous solubility. To increase the aqueous solubility and decrease the gastrointestinal irritation, capsaicin was complexed with phospholipid. A phospholipid complex was prepared and characterized through x-ray diffraction, differential scanning calorimetry, and Fourier-transform infrared spectroscopy. The prepared phospholipid complexes were studied for solubility, in vitro drug release and in vitro cytotoxicity. Molecular interaction between capsaicin and phospholipid was identified through Fourier-transform infrared spectroscopy, which confirmed the formation of phospholipid complex. X-ray diffractometer and differential scanning calorimetry results indicated reduced crystallinity of capsaicin in the complex. The solubility of the capsaicin was found to be enhanced 1.7 and 2.6 fold in 1:1 and 1:2 complex in comparison to free capsaicin. In dissolution studies, the phospholipid complex exhibited a higher rate of drug release compared to the free drug. Phospholipid complex showed more cytotoxic potential on MCF-7 and MDA-MB-231 human breast cancer cells compared to free capsaicin in an MTT assay that measures metabolic activity. The present study demonstrated that a phospholipid complex of capsaicin overcomes the problems related to the poor aqueous solubility and could be used as effective delivery carrier for cancer therapy.
\end{abstract}

Key words: Capsaicin, phospolipid complex, drug delivery, cancer, cytotoxicity

Cancer is the main causes of morbidity throughout the world ${ }^{[1-2]}$. Among the different cancers, breast cancer is the second most important cause of cancer death. Though significant progress has been made in breast cancer treatment, only a few patients benefit from breast cancer by adjuvant chemotherapy and most patients with metastatic cancer are resistant to chemotherapy ${ }^{[3]}$. In addition, chemotherapy causes acute and chronic toxicities that include sterility, congestive heart failure, osteoporosis and neuropathy ${ }^{[4]}$. Recently, many new avenues of cancer treatment have opened up but the costs of treatment have sky-rocketed too. Hence, screening of indigenously available plant and animal resources for anticarcinogenic potential is an important branch of anticancer research. Chili peppers are the regularly consumed naturally occurring spices worldwide ${ }^{[5-6]}$. Capsaicin, (8-methyl-N-vanillyl-6nonenamide, fig. 1a) is the main constituent of chili peppers with therapeutic activity ${ }^{[7]}$. The chemical formula of capsaicin is $\mathrm{C}_{18} \mathrm{H}_{27} \mathrm{NO}_{3}$ and the molecular weight is $305.4 \mathrm{~g} / \mathrm{mol}^{[8]}$. Capsaicin is a hydrophobic, colourless, pungent and volatile crystalline powder. It has a benzene ring and a polar amide group with a long hydrophobic carbon tail. Due to its water insolubility, alcohols and organic solvents are used to dissolve capsaicin.

Capsaicin induces apoptosis in several cancer cell lines including liver cancer, prostate cancer, colon cancer, pancreatic cancer, and breast cancer without affecting normal cells ${ }^{[9]}$. In human breast cancer, epidermal growth factor-2 (HER-2) and human epidermal growth factor receptor are over expressed ${ }^{[10,11]}$. Capsaicin inhibited breast cancer cell growth in vitro by reducing the protein expression of human epidermal growth factor receptor and epidermal growth factor- $2^{[12]}$.

This is an open access article distributed under the terms of the Creative Commons Attribution-NonCommercial-ShareAlike 3.0 License, which allows others to remix, tweak, and build upon the work non-commercially, as long as the author is credited and the new creations are licensed under the identical terms

Accepted 18 September 2019

Revised 12 June 2019

Received 24 March 2019

${ }^{*}$ Address for correspondence E-mail: tapan_ju01@rediffmail.com

November-December 2019
Indian J Pharm Sci 2019;81(6):1011-1019 
Moreover, capsaicin decreased by $50 \%$ of the size of breast cancer tumours in immunodeficient mice. In another study, capsaicin has been shown to inhibit the growth of MCF-7 breast cancer cell through a caspasedependent pathway and induced DNA fragmentation ${ }^{[13]}$. Breast cancer patients are resistant to chemotherapy due to lack of caspase-3 expression. Capsaicin also induces apoptosis in caspase-3 deficient MCF-7 and BT-20 breast cancer cells ${ }^{[14]}$. Capsaicin significantly diminished procaspase-7 expression, induced the cleavage of PARP-1 and decreased membrane potential of mitochondria in MCF-7 and BT-20 breast cancer cell.

In spite of its proven anticancer activity, the clinical utilization of capsaicin is limited due to its short half-life and rapid first-pass metabolism ${ }^{[15]}$. It is hughly irritating to skin and mucosa, causing a burning sensation, even in low concentrations ${ }^{[16]}$. The pungency of capsaicin may increase salivation and gastrointestinal disorders when administered orally ${ }^{[17]}$. Tyagi et al. developed capsaicinloaded liposomes and thermosensitive hydrogel for intravesical therapy of detrusor hyperreflexia ${ }^{[18]}$. It was observed that capsaicin-loaded liposomes completely blocked micturition reflexes. However, hydrogel loaded with capsaicin did not totally block the micturition reflex but it extensively diminished the frequency of bladder contraction. In another study, capsaicin was complexed with hydroxypropyl-betacyclodextrin and incorporated into the hydrogel to improve the solubility and percutaneous absorption ${ }^{[19]}$. It was observed that the complexing agent enhanced the solubility and percutaneous permeation of capsaicin. Though there have been some attempts to improve the solubility and bioavailability of capsaicin ${ }^{[20,21]}$, it is yet to be developed in a standard anticancer dosage form.

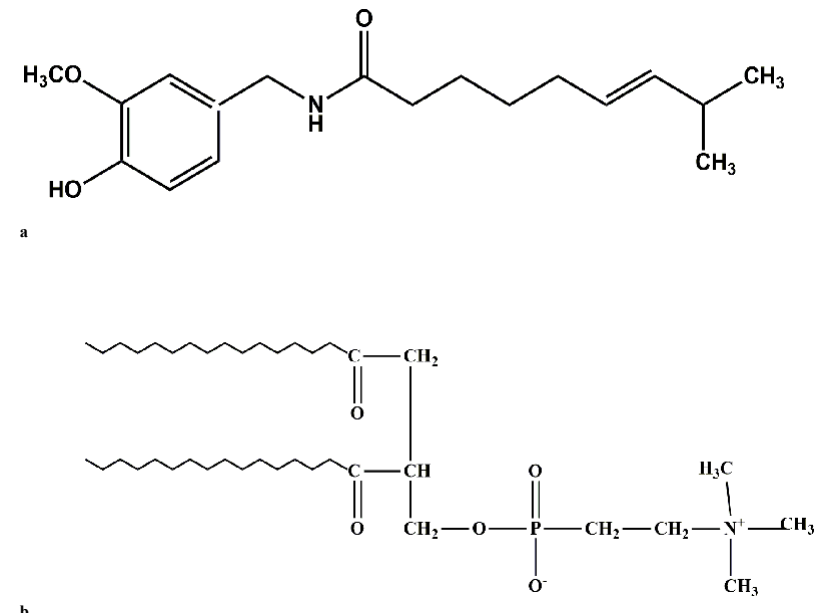

Fig. 1: Chemical structure of (a) capsaicin and (b) phospholipid
Recently, phospholipid complex plays an important role in the delivery of drug and it enhances the solubility and bioavailability of drug ${ }^{[22]}$. The major component of the biological membrane is phospholipid (fig. 1b) and composed of a hydrophobic tail and hydrophilic head ${ }^{[23]}$. It enters the cytoplasm without lipid bilayers disruption and enhances oral drug absorption ${ }^{[24]}$. Soybean phospholipids are extensively used for the phospholipid complex preparation ${ }^{[25]}$. In the present study, the development of a capsaicin-loaded phospholipid complex and evaluation of cytotoxicity on human breast cancer cells is reported.

\section{MATERIALS AND MEHODS}

Capsaicin (purity $99.8 \%$ ) was purchased from Naturite Agro Products Ltd. (Hyderabad, India). Soya lecithin was purchased from Himedia, India. The analytical grade of other chemicals was used without any further purification.

\section{Preparation of capsaicin phospholipid complex:}

Phospholipids complex were prepared by refluxing followed by evaporation of the solvent. The required quantity of capsaicin was taken in a beaker containing $10 \mathrm{ml}$ ethanol to dissolve it. A measured quantity of phospholipids was taken in another beaker containing $20 \mathrm{ml}$ ethanol and stirred to solubilize the phospholipids. Then the capsaicin solution was poured into the phospholipids solution with stirring at $50^{\circ}$ for $2 \mathrm{~h}$ and the solvent was removed. The resultant mixture was put into a vacuum desiccator for $24 \mathrm{~h}$ to get a complete dry substance. The dried product was stored in a desiccator for further use.

\section{Fourier-transform infrared spectroscopy (FTIR) study:}

FTIR spectra of capsaicin, phospholipids, capsaicin and phospholipids physical mixture (1:2), and 1:2 complexes of capsaicin and phospholipids were measured on FTIR spectrophotometer (Alpha-T, Bruker, Germany). Approximately, $2 \mathrm{mg}$ of samples were mixed with $200 \mathrm{mg}$ of $\mathrm{KBr}$ and compressed to prepare circular discs. The sample was scanned with $4 \mathrm{~cm}^{-1}$ spectral resolution over a range of 4000 $500 \mathrm{~cm}^{-1[26]}$.

\section{Differential scanning calorimetry (DSC) study:}

DSC studies of capsaicin, capsaicin and phospholipids physical mixture (1:2) and 1:2 complexes of capsaicin and phospholipids were carried out using DSC (Pyris 
Diamond, Perkin Elmer, Osaka, Japan). Samples were heated with $10^{\circ} / \mathrm{min}$ heating rate from $30-300^{\circ}$ in a nitrogen atmosphere (flow rate, $20 \mathrm{ml} / \mathrm{min})^{[27]}$.

\section{X-ray diffraction (XRD) study:}

XRD studies of capsaicin, capsaicin and phospholipids physical mixture (1:2) and 1:2 complexes of capsaicin and phospholipids were carried out using XRD (Smart Lab, Rigaku, Japan). The tube voltage and current were set at $45 \mathrm{kV}$ and $200 \mathrm{~mA}$, respectively. The sample was placed in an aluminium sample holder and scan between $5-80^{\circ}$ in $2 \theta$ with a $0.04^{\circ} / \mathrm{min}$ step size with a scan speed of $5^{\circ} / \mathrm{min}^{[28]}$.

\section{Solubility studies:}

The solubility of capsaicin was determined in a volumetric flux by adding an excess amount of capsaicin to $10 \mathrm{ml}$ of water and sonicated for $1 \mathrm{~h}$. Then, the mixture was shaken for $24 \mathrm{~h}$ (BOD Shaker, India) at $37 \pm 0.5^{\circ}$ and centrifuged at $15000 \mathrm{rpm}$ for $15 \mathrm{~min}$. The supernatant was filtered through a Whatman number 1 filter paper and absorbance was measured at $279 \mathrm{~nm}$ by UV/Vis spectrophotometer (UV 1800, Shimadzu, Japan) to determine the solubility of capsaicin in the solute. Each experiment was performed 3 times.

\section{In vitro drug release study:}

The release of a drug was performed in a beaker containing release media, $\mathrm{pH} 1.2 \mathrm{KCl} / \mathrm{HCl}$ buffer for $2 \mathrm{~h}$ and $\mathrm{pH} 7.4$ phosphate buffer for the remaining time, kept on a magnetic stirrer with $300 \mathrm{rpm}$ rotation at $37^{\circ}$. A known amount of sample was taken in a dialysis bag (Himedia, Mumbai, India) and the bag ends were bound with the thread. Then the dialysis bag was dipped into the buffer solution. The samples were withdrawn at a fixed time interval with replacement of the buffer solution. The solutions were filtered through a Whatman number 1 filter paper and drug content was determined by UV/Vis spectrophotometer at $279 \mathrm{~nm}$ with the respective buffer solution as a blank. The mean dissolution time (MDT) was determined to understand the formulations dissolution performance. MDT was calculated using the following Eqn. ${ }^{[29]}$, MDT = $\sum_{j=1}^{\mathrm{n}} \mathrm{t}^{\prime \prime} j \Delta \mathrm{M}_{\mathrm{i}} / \sum_{j=1}^{\mathrm{n}} \Delta \mathrm{M}_{\mathrm{i}}$, where $\mathrm{n}$ is the number of sample times, $\mathrm{j}$ is the sample number, $\mathrm{t}$ " is the time at the midpoint between $t_{j}$ and $t_{j-1}$ and $\Delta M_{i}$ is the drug dissolved between $t_{i}$ and $t_{i-1}$.

\section{In vitro cytotoxicity study:}

The cytotoxic effect of capsaicin-loaded phospholipid complex was determined through [3-(4,5-dimethylthiazol-2-yl)-2,5-diphenyltetrazolium bromide (MTT) assay where viable cell's reducing enzymes convert MTT to formazan crystals. The cytotoxicity was performed using MCF-7 and MDA-MB-231 breast cancer cell lines using MTT assay for assessing cell metabolic activity. Roswell Park Memorial Institute medium (RPMI 1640) and Dulbecco's modified Eagle medium were used to culture MDA-MB-231and MCF-7cells, respectively. Five percent fetal bovine serum and $1 \%$ antibiotic were added to both media. All reagents were purchased from Himedia (Mumbai, India). The cells were incubated in $5 \% \mathrm{CO}_{2}$ and humidified atmosphere at $37^{\circ}$. MDA-MB-231 and MCF-7 cells were seeded in a two different 96-well culture plate and incubated for overnight. Four different doses $(100,150,225$, and $300 \mu \mathrm{M})$ were selected for the treatment of cells with a drug, blank formulation and drug-loaded formulation in $150 \mu \mathrm{l}$ complete media for $24 \mathrm{~h}$. After incubation at $37^{\circ}$ for $24 \mathrm{~h}$, each well was added with $50 \mu \mathrm{l}$ of MTT reagent $(5 \mathrm{mg} / \mathrm{ml})$. Then the cells were incubated at $37^{\circ}$ for another $4 \mathrm{~h}$. After removal of the MTT solution, the formazan crystals (purple) produced at the wells were solubilized using $150 \mu \mathrm{D}$ DMSO with shaking for $30 \mathrm{~s}$. Then, the absorbance was recorded at 570 and $650 \mathrm{~nm}$ by Spectramax (Molecular Devices, USA). The following Eqn. was used to determine the cell viability, cell viability $(\%)=(\mathrm{T} / \mathrm{C}) \times 100$, where $\mathrm{T}$ is the optical density of the treated cells and $\mathrm{C}$ is the optical density of control cells.

\section{RESULTS AND DISCUSSION}

Development of a novel drug delivery system using natural resources is essential due to the advantage of an herbal drug for the treatment of different diseases. In the phospholipid complex, it was speculated that capsaicin's nonpolar functional group forming quasistable bonding with phospholipid and consequently hydrophobic moiety was masked ${ }^{[30]}$. The phospholipid is a vital constituent of cell membranes and promotes drug transport from the gastrointestinal (hydrophilic) milieu to the intestinal cell membrane (lipophilic) and finally into the blood ${ }^{[31]}$. In the present experiment, a capsaicin phospholipid complex was prepared by a simple and reproducible method.

The interaction between the phospholipids and capsaicin was determined to confirm the complex formation. Hydrogen bond or van der Waals forces were formed in the phospholipid complex ${ }^{[32,33]}$. FTIR studies were carried out to explore the type of interaction between 
capsaicin and phospholipid. FTIR spectra of capsaicin and phospholipid are represented in fig. 2. Capsaicin is depicted peak at $3447 \mathrm{~cm}^{-1}$ due to broadened N-H and $\mathrm{O}-\mathrm{H}$ stretch (fig. 2). The peaks showed at $1633 \mathrm{~cm}^{-1}$ represents $\mathrm{C}=\mathrm{O}$ stretch and at $1516 \mathrm{~cm}^{-1}$ for $\mathrm{N}-\mathrm{H}$ bends. The peak shown at $1283 \mathrm{~cm}^{-1}$ represents $\mathrm{C}-\mathrm{N}$ bonds stretching and the peak depicted at $806 \mathrm{~cm}^{-1}$ for out of plane $\mathrm{C}-\mathrm{H}$ bend. A similar observation was reported by the other authors ${ }^{[34]}$. The peaks in phospholipid showed at $3010,2925,2855 \mathrm{~cm}^{-1}$ represented strong stretching vibration of $-\mathrm{CH}_{3},-\mathrm{CH}_{2}$ and $-\mathrm{CH}$, respectively (fig. 2) in the phosphate group. The peak at $3408 \mathrm{~cm}^{-1}$ represented $-\mathrm{OH}$ stretching vibration of phospholipid. The peak at $1736 \mathrm{~cm}^{-1}$ represented $\mathrm{C}=\mathrm{O}$ stretching vibration of the ester group. The peak shown at $1230 \mathrm{~cm}^{-1}$ represented the $\mathrm{P}=\mathrm{O}$ stretching of a phosphate group. The peak at $1070 \mathrm{~cm}^{-1}$ represented stretching of P-O-C of a phosphate group. A similar observation was reported by the other workers ${ }^{[35,36]}$.

FTIR spectra of physical mixture and phospholipid complex are represented in fig. 2. Capsaicin peaks of $\mathrm{C}=\mathrm{O}$ stretch, $\mathrm{N}-\mathrm{H}$ bends, $\mathrm{C}-\mathrm{N}$ bonds stretching, and $\mathrm{C}-\mathrm{H}$ bend were observed at 1629, 1516, 1282, and $808 \mathrm{~cm}^{-1}$ in the physical mixture. Similarly, phospholipid $-\mathrm{CH}_{3}$ vibration, $\mathrm{CH}_{2}$ vibration, $\mathrm{CH}$ vibration, $\mathrm{C}=\mathrm{O}$ stretch, $\mathrm{P}=\mathrm{O}$ stretch, and $\mathrm{P}-\mathrm{O}-\mathrm{C}$ stretch are observed at 3010, 2925, 2855, 1736, 1230, and $1070 \mathrm{~cm}^{-1}$ in the physical mixture. The physical mixture of capsaicin and phospholipids showed almost similar FTIR spectra of capsaicin and phospholipid with slight changing of few peaks compared to the pure drug (fig. 2). This shift of peaks may be occurred due to the development of some weak forces amongst the capsaicin and phospholipid. The peak at $3448 \mathrm{~cm}^{-1}$ due to $\mathrm{N}-\mathrm{H}$ and $\mathrm{O}-\mathrm{H}$ stretch of capsaicin was not observed in the physical mixture, possibly due to shielding by the phospholipid molecule. The phospholipid complex of capsaicin and phospholipids showed changing of peaks in comparison to drug and physical mixture (fig. 2). The IR of the complex showed a shift in phenolic -OH of capsaicin from 3447 to $3314 \mathrm{~cm}^{-1}$. Similarly, the phospholipid peaks at 1230 and $1070 \mathrm{~cm}^{-1}$ were not observable in the complex spectrum. These changes indicated that capsaicin and phospholipids formed a complex by hydrogen bonding between the capsaicin phenolic $-\mathrm{OH}$ group and the $\mathrm{P}=\mathrm{O}$ group of the phospholipids ${ }^{[37]}$.

DSC is a technique for the thermal analysis of a broad diversity of materials. Changes in material properties with changes in the temperature can give valuable
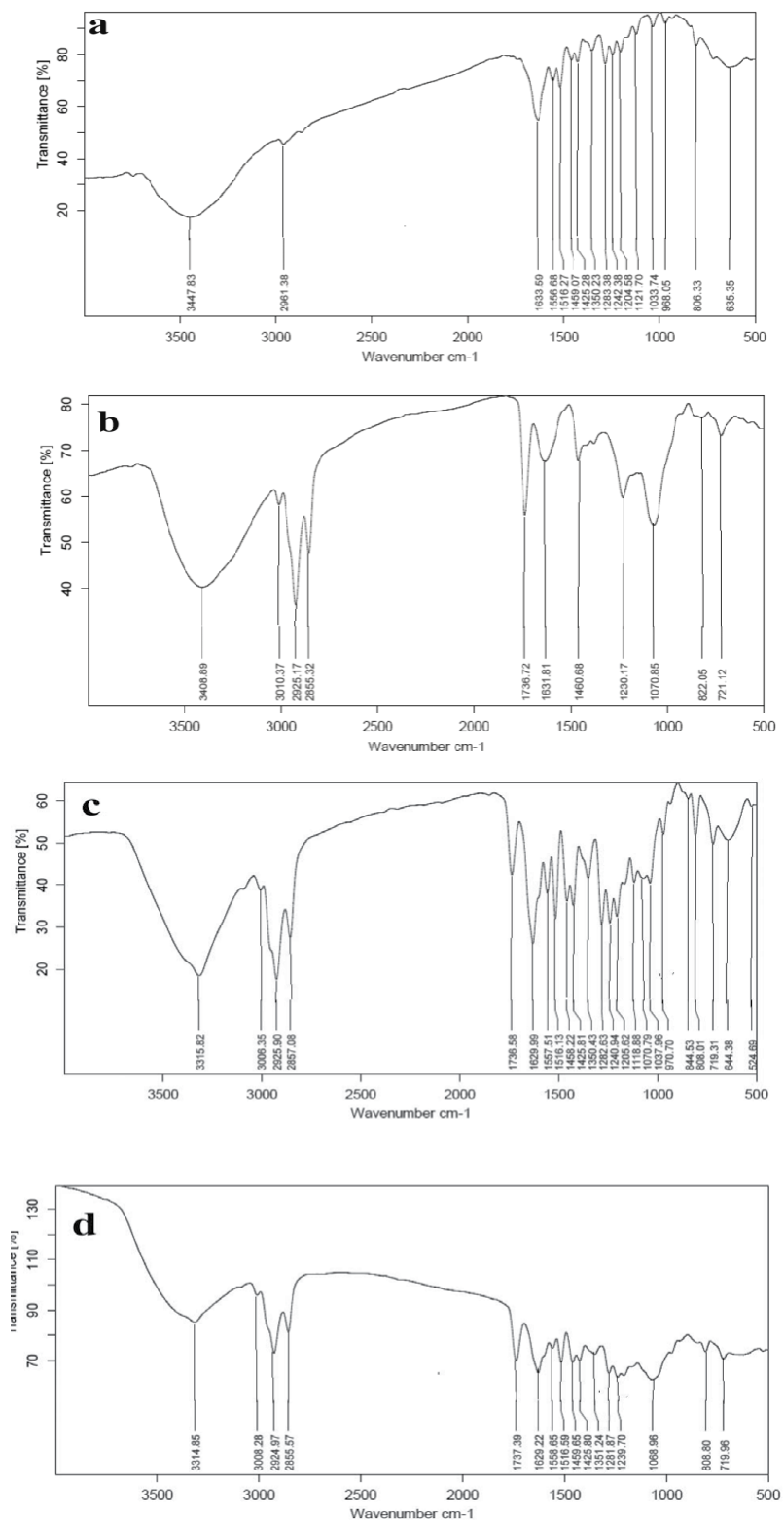

Fig. 2: FTIR spectra of capsaicin, phospholipids, physical mixture and phospholipid complex

FTIR spectra of (a) free capsaicin, (b) phospholipids (c) capsaicin and phospholipid physical mixture (1:2) and (d) capsaicin and phospholipid complex (1:2)

information about the drug-excipient interactions and new entities formation. Fig. 3 showed differential scanning thermograms of the capsaicin, physical mixture of capsaicin and phospholipids, and complex of capsaicin and phospholipids. Pure capsaicin (fig. 3a) showed a sharp endothermic (melting) peak at $66^{\circ}$, representing capsaicin crystalline nature. Similar melting endotherm was observed by another author ${ }^{[38]}$. The thermogram of the physical mixture (fig. 3 b) exhibited peaks at $65^{\circ}$, slightly lower than pure capsaicin. It was shown that an increase in temperature might cause melting of individual constituents and form aggregates of capsaicin and phospholipids whose 
melting point is lower than capsaicin ${ }^{[39]}$. Thermograms of the complex (fig. 3c) showed two new peaks at $31^{\circ}$ and $58^{\circ}$, which is different from the capsaicin peak. There is a complex formation through weak intermolecular interaction (hydrogen bonding, van der Waals interactions) between capsaicin and phospholipid. These interactions possibly allow the fatty acid chains of the phospholipid molecule to rotate freely and surround the capsaicin molecule, thus dispersing the capsaicin molecule into the phospholipid molecule at a molecular level. Such complex formation might contribute to an enhancement in the dissolution profile of capsaicin. In another study, naringenin showed melting endothermic peak at $253^{\circ}$ and complex showed two new peaks at $51^{\circ}$ and $62^{\circ}[40]$. They concluded that naringenin complex with phospholipids through hydrogen bonding and hydrophobic interaction. In the present study, the $-\mathrm{OH}$ groups of the capsaicin phenol rings might be involved in hydrogen bonding while the aromatic rings could be involved in hydrophobic interaction. These DSC data are supported by the outcome of the DSC profile of the phospholipid complexes prepared by other authors ${ }^{[41,42]}$.

XRD study was carried to check the crystalline properties of the drug in the formulation ${ }^{[43]}$. X-ray powder diffraction of capsaicin, physical mixture, and complex was shown in fig. 4. Capsaicin exhibited intense diffraction peaks (fig. 4a) at $2 \theta=5.8^{\circ}$ (258226), $11.7^{\circ}$ (35705), $16.6^{\circ}$ (32673), and $19.9^{\circ}$ (21480) representing the crystalline properties of a drug. Similarly, diffraction peaks of capsaicin at $5.8^{\circ}, 11.7^{\circ}$, $16.4^{\circ}$, and $19.8^{\circ}$ were observed by other authors ${ }^{[38]}$. The diffractogram of the physical mixture showed

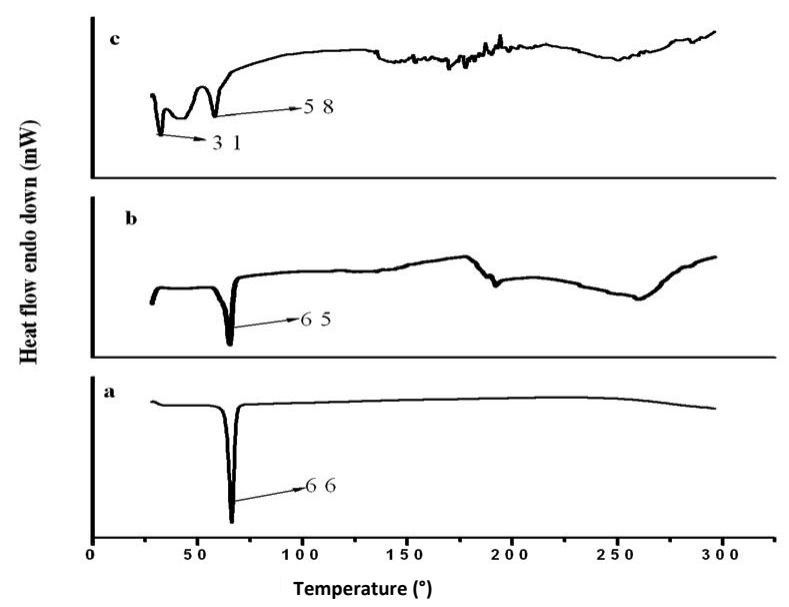

Fig. 3: DSC thermograms of capsaicin, physical mixture and phospholipid complex

DSC thermogram of (a) free capsaicin (b) capsaicin and phospholipid physical mixture (1:2) and (c) capsaicin and phospholipid complex (1:2)

November-December 2019 diffraction peaks (fig. $4 \mathrm{~b}$ ) at $2 \theta=5.8^{\circ}(8352), 11.7^{\circ}$ (8352), $16.6^{\circ}(10361)$, and $19.9^{\circ}(13130)$ representing reduced capsaicin peak. Moreover, the diffraction peak at $19.9^{\circ}(13130)$ was wider and this may be the combined peak of capsaicin and phospholipid. The broad peak of phospholipid around $2 \theta=20.1^{\circ}$ was observed by other authors $^{[44]}$. This decrease might be due to the lesser amount of capsaicin in the mixture or formation of aggregates between capsaicin and phospholipid ${ }^{[45]}$. The diffractogram of the complex showed peaks (fig. 4c) at $2 \theta=5.8^{\circ}(8121), 11.7^{\circ}(7184), 16.6^{\circ}$ (8014), and $19.9^{\circ}(9455)$ representing more reduced capsaicin peak compared to the physical mixture. This indicated that the crystallinity of drug in the complex was decreased and that most of the drugs existed in an amorphous form with a minority in the crystalline state. The preparation of complex with reduced crystallinity might facilitate the dissolution process, which was desirable mainly due capsaicin have low solubility in aqueous media. Similar results were obtained by earlier studies with diclofenac phospholipid complexes ${ }^{[46]}$.

Solubility studies were carried out to see the solubility enhancement of capsaicin in a complex formulation. A marked improvement in aqueous solubility of capsaicin was observed in the phospholipid complex formulation (Table 1). The aqueous solubility of the drug increased significantly in 1:1 complex $(\mathrm{p}<0.05)$ and 1:2 complex $(\mathrm{p}<0.05)$ compared to pure drug. The aqueous solubility of the drug was increased 1.7 fold in 1:1 complex and 2.6 fold in 1:2 complex compared to pure drug. The 1:1 and 1:2 physical mixtures of capsaicin and phospholipids failed to show any significant increase in aqueous solubility of capsaicin. The increase in solubility of capsaicin in the complex formulation can be explained by partial amorphization of the capsaicin, the creation of micelle due to phospholipids amphiphilic nature and wetting of the capsaicin in the phospholipids ${ }^{[47,48]}$.

In vitro dissolution behaviour of pure capsaicin, physical mixture and prepared complex in hydrochloric acid buffer solutions ( $\mathrm{pH}$ 1.2) and phosphate buffer solutions $(\mathrm{pH} 7.4)$ are represented in fig. 5. About $18 \%$ of the free drug was released at the end of $8 \mathrm{~h}$ of dissolution study. The physical mixture of a drug to phospholipid molar ratios of 1:1 and 1:2 released about $26 \%$ drug at the end of $8 \mathrm{~h}$ of dissolution study. Dissolution rate enhancement of physical mixture could be due to phospholipid amphiphilic nature and enhanced the aqueous solubility of the drug by the 


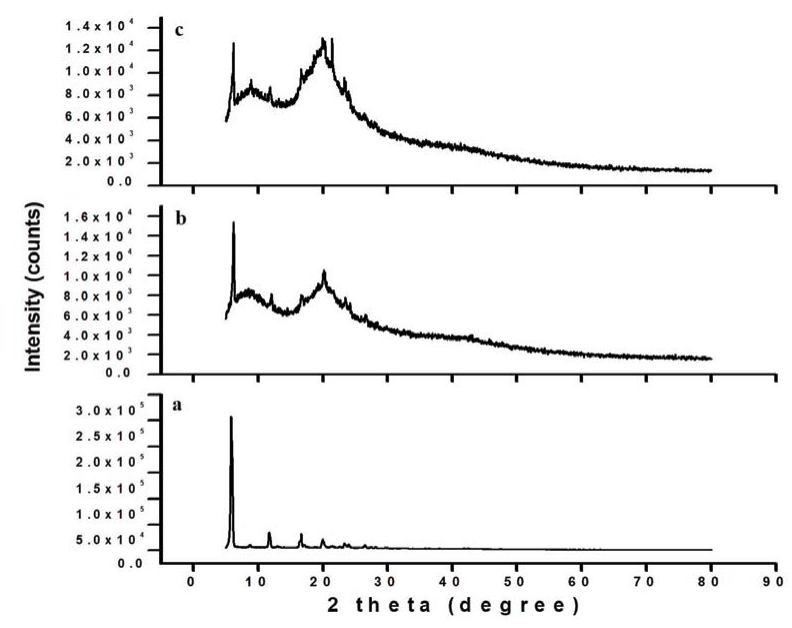

Fig. 4: X-ray diffractograms of capsaicin, physical mixture and capsaicin phospholipid complex

X-ray diffractograms of (a) free capsaicin (b) capsaicin and phospholipid physical mixture (1:2) and (c) capsaicin and phospholipid complex (1:2)

action of dispersion and wetting ${ }^{[40]}$. Phospholipid complex of a drug to phospholipid molar ratios of 1:1 and 1:2 released 32 and $50 \%$ drug respectively, at the end of $8 \mathrm{~h}$ of dissolution study. The enhanced release rate of the drug was observed from the phospholipid complex compared to free drug and physical mixture. The increase in the release rate of capsaicin from the complexes can be ascribed to the improved solubility and enhanced wettability of capsaicin in the prepared phospholipid complex ${ }^{[49,50]}$. Table 2 shows the MDT of different formulations and lower MDT was observed in the case of 1:2 complexes. The lower the MDT the faster the release rate. MDT was decreased significantly $(\mathrm{p}<0.05)$ with an increasing drug to lipid ratio from 1:1 to $1: 2$ compared to pure capsaicin.

The faster drug release and lower MDT were obtained from phospholipid complex with drug and phospholipid ratio of 1:2. So, this formulation was chosen for the cytotoxicity study. The effects of capsaicin-loaded phospholipid complex as well as capsaicin solution on the viability of the MCF-7 and MDA-MB-231 human breast cancer cells were examined by MTT assay. The outcome of the MTT assay were represented in figs. 6a and b. It was observed that both capsaicin-loaded phospholipid complex and pure capsaicin exerted cytotoxicity activity. Phospholipid complex enhanced the cytotoxicity of capsaicin in comparison to the free capsaicin after $24 \mathrm{~h}$. The survival of breast cancer cells upon incubation of capsaicin and phospholipid complex formulation in different concentration was presented in Table 3. Dose-dependent cytotoxicity was observed in both drug solution and phospholipid complex formulation and cell viability reduced upon increasing the capsaicin concentration.

When MDA-MB-231 breast cancer cells were treated with capsaicin, the $\%$ cell viability at $100,150,225$, and $300 \mu \mathrm{M}$ concentration of capsaicin were 87,80 , 66 and 47, respectively (Table 3). Similarly, cells were treated with a formulation, the $\%$ cell viability at a same equivalent concentration of capsaicin was 75,74 , 66 , and 45, respectively (Table 3 ). Both capsaicin and phospholipid formulation containing capsaicin reduced cell viability significantly $(p<0.05)$ with increasing concentration of capsaicin. MCF-7 cells were treated with capsaicin, the \% cell viability at 100, 150, 225, and $300 \mu \mathrm{M}$ concentration of capsaicin were $84,81,79$ and 78, respectively (Table 3 ). Cells were treated with a formulation, the $\%$ cell viability at a same equivalent concentration of capsaicin was 82, 79, 77, and 76, respectively (Table 3 ). Both capsaicin and phospholipid complex formulation containing capsaicin reduced cell viability with increasing concentration of capsaicin without statistical significance $(\mathrm{p}>0.05)$. Chang et al. reported that the capsaicin reduced the viability of a cancer cell in a dose-dependent manner and arresting the cell cycle in the S phase in BT-20 and MCF-7 breast cancer cells ${ }^{[14]}$. Phospholipid complex was cytotoxic to a greater degree in both MCF-7 and MDA-MB-231

\begin{tabular}{|c|c|}
\hline Formulation & ubility $(\mu \mathrm{g} / \mathrm{l} ;$ mean $\pm S D, n=3)$ \\
\hline Capsaicin & $0.04 \pm 0.002$ \\
\hline Physical mixture $(1: 1)$ & $0.04 \pm 0.006$ \\
\hline Physical mixture $(1: 2)$ & $0.04 \pm 0.001$ \\
\hline Complex $(1: 1)$ & $0.07 \pm 0.002$ \\
\hline Complex $(1: 2)$ & $0.11 \pm 0.006$ \\
\hline
\end{tabular}

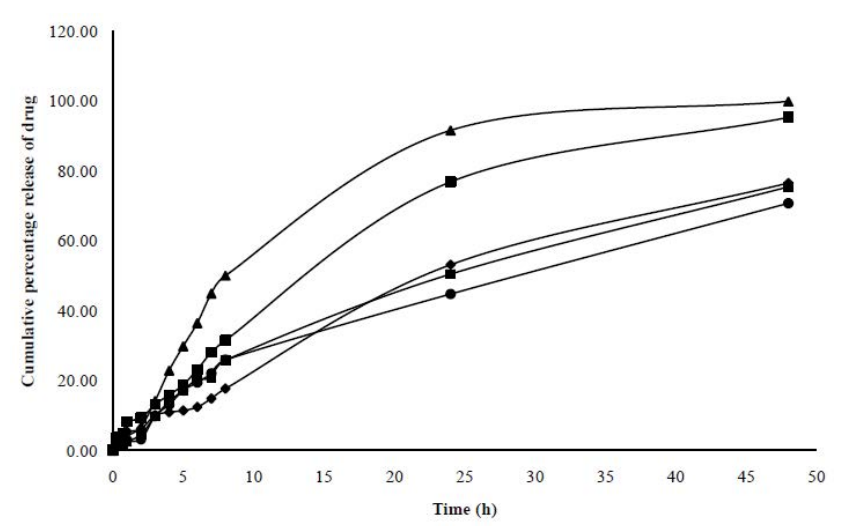

Fig. 5: In vitro dissolution profiles of capsaicin from capsaicin suspension, physical mixture and phospholipid complex

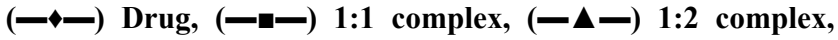
(一॰-) 1:1 physical mixture, (-匹-) 1:2 physical mixture 
TABLE 2: MEAN DISSOLUTION TIME OF DIFFERENT FORMULATIONS

\begin{tabular}{|c|c|c|c|c|c|c|c|}
\hline (mear & $\begin{array}{l}\text { Drug } \\
1 \pm S D, n=3)\end{array}$ & $\begin{array}{l}\text { 1:1 phys } \\
\text { (mean }\end{array}$ & $\begin{array}{l}\text { al mixture } \\
D, n=3 \text { ) }\end{array}$ & $\begin{array}{l}1: 2 \\
(\mathrm{~m}\end{array}$ & $\begin{array}{l}\text { sical mixture } \\
n \pm S D, n=3)\end{array}$ & $\begin{array}{c}1: 1 \text { complex } \\
(m e a n \pm S D, n=3)\end{array}$ & $\begin{array}{c}1: 2 \text { complex } \\
(m e a n \pm S D, n=3)\end{array}$ \\
\hline MDT & $5 \pm 0.02$ & & 0.05 & & $7 \pm 0.11$ & $6.2 \pm 0.29$ & $4.6 \pm 0.07$ \\
\hline $\begin{array}{l}\text { TABLE 3: C } \\
\text { CAPSAICIN }\end{array}$ & OTOX & & $C A D$ & & DHos & ID & IING \\
\hline & & & & ell vi & ity at different $\mathrm{CC}$ & oncentrations of caps & saicin \\
\hline cell line & Form & ation & $\begin{array}{r}100 \\
(\text { mean } \pm \text { SI }\end{array}$ & & $\begin{array}{c}150 \mu \mathrm{M} \\
(\text { mean } \pm S D, n=3)\end{array}$ & $\begin{array}{c}225 \mu M \\
(m e a n \pm S D, n=3)\end{array}$ & $\begin{array}{c}300 \mu M \\
(m e a n \pm S D, n=3)\end{array}$ \\
\hline ADA $\triangle A P 221$ & Cap & icin & $87 \pm 4$ & & $80 \pm 5.1$ & $66 \pm 4.7$ & $47 \pm 4.2$ \\
\hline MUDA-MVD-ZJI & Phospholi & complex & $75 \pm 4$ & & $74 \pm 3.9$ & $66 \pm 2.9$ & $45 \pm 3.6$ \\
\hline MCF-7 & Cap & icin & $84 \pm 1$ & & $81 \pm 3.3$ & $79 \pm 4.3$ & $78 \pm 4.2$ \\
\hline MCr-I & Phospholi & d complex & $82 \pm 1$ & & $79 \pm 2.3$ & $77 \pm 4.1$ & $76 \pm 8.4$ \\
\hline
\end{tabular}
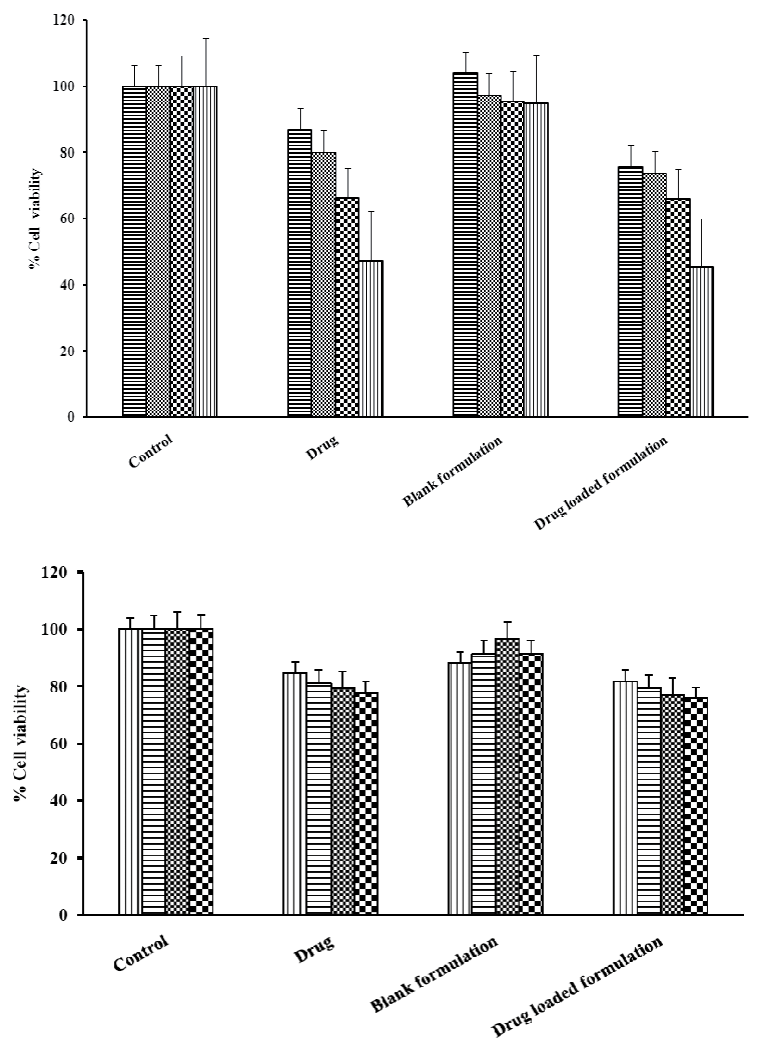

b

Fig. 6: Effect of free capsaicin, blank formulation and drugloaded formulation on \% viability of MDA-MB-231 and MCF7 cell line

$\%$ Cell viability of (a) MDA-MB-231 cell line and (b) MCF-7 cell line after 24 exposure to free capsaicin, blank formulation and drug-loaded formulation. a. (无) $100 \mu \mathrm{M}$, (\&) $150 \mu \mathrm{M}$,

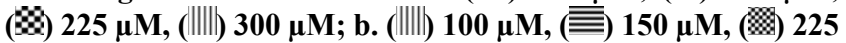
$\mu \mathrm{M}$, (8) $300 \mu \mathrm{M}$

cells compared to plain capsaicin. The augmented effect of these phospholipid complexes could be ascribed to the improved aqueous solubility and dissolution rate of capsaicin.

In the present investigation, capsaicin-phospholipid complex was prepared using a solvent evaporation technique. The physicochemical investigations showed that capsaicin formed a complex with phospholipids. The drug entrapped into the phospholipid complex and the solubility was increased 1.7 and 2.6 fold for $1: 1$ and 1:2 complexes in comparison to pure drug. The release study revealed that the phospholipid complex exhibited enhanced drug release compared to pure capsaicin. The in vitro cytotoxicity studies on MCF-7 and MDA-MB-231 human breast cancer cells showed that capsaicin-loaded phospholipid complex have greater cytotoxicity than capsaicin solution and blank phospholipid complex. Capsaicin-loaded phospholipid complex can be considered as a potential carrier for breast cancer therapy.

\section{REFERENCES}

1. Dey M, Das M, Chowhan A, Giri TK. Breaking the barricade of oral chemotherapy through polysaccharide nanocarrier. Int J Biol Macromol 2019;130:34-49.

2. Giri TK. Breaking the barrier of cancer through liposome loaded with phytochemicals. Curr Drug Deliv 2019;16(1):317.

3. Gonzalez-Angulo AM, Morales-Vasquez F, Hortobagyi GN. Overview of resistance to systemic therapy in patients with breast cancer. Adv Exp Med Biol 2007;608:1-22.

4. Rock E, DeMichele A. Nutritional approaches to late toxicities of adjuvant chemotherapy in breast cancer survivors. J Nutr 2003;133:3785-93.

5. Giri TK, Pramanik K, Barman TK, Maity S. Nanoencapsulation of dietary phytoconstituent capsaicin on emulsome: evaluation of anticancer activity through the measurement of liver oxidative stress in rats. Anticancer Agents Med Chem 2017;17:1669-78.

6. Giri TK, Bhowmick S, Maity S. Entrapment of capsaicin loaded nanoliposome in $\mathrm{pH}$ responsive hydrogel beads for colonic delivery. J Drug Deliv Sci Technol 2017;39:417-22.

7. Giri TK, Thakur A, Tripathi DK. Biodegradable hydrogel bead of casein and modified xanthan gum for controlled delivery of theophylline. Curr Drug Ther 2016;11:150-62.

8. O’Neill J, Brock C, Olesen AE, Andresen T, Nilsson M, Dickenson AH. Unravelling the mystery of capsaicin: A tool to understand and treat pain. Pharmacol Rev 2012;64:939-71.

9. Bley KB, Boorman G, Mohammad B, McKenzie D, 
Babbar S. A Comprehensive review of the carcinogenic and anticarcinogenic potential of capsaicin. Toxicol Pathol 2012;40:847-73.

10. Mendelsohn J, Baselga J. Status of epidermal growth factor receptor antagonists in the biology and treatment of cancer. $\mathrm{J}$ Clin Oncol 2003;21:2787-99.

11. Menard S, Pupa SM, Campiglio M, Tagliabue E. Biologic and therapeutic role of HER2 in cancer. Oncogene 2003;22:65708.

12. Thoennissen NH, O'Kelly J, Lu D, Iwanski GB, La DT, Abbassi $\mathrm{S}$, et al. Capsaicin causes cell-cycle arrest and apoptosis in ER-positive and -negative breast cancer cells by modulating the EGFR/HER-2 pathway. Oncogene 2010;29:285-96.

13. Tuoya, Baba N, Shimoishi Y, Murata Y, Tada M, Koseki M, et al. Apoptosis induction by dohevanil, a DHA substitutive analog of capsaicin, in MCF-7 cells. Life Sci 2006;78:1515-9.

14. Chang HC, Chen ST, Chien SY, Kuo SJ, Tsai HT, Chen DR. Capsaicin may induce breast cancer cell death through apoptosis-inducing factor involving mitochondrial dysfunction. Hum Exp Toxicol 2011;30:1657-65.

15. Kawada T, Watanabe $T$, Katsura K, Takami H, Iwai K. Formation and metabolism of pungent principle of capsicum fruits. XV. Microdetermination of capsaicin by highperformance liquid chromatography with electrochemical detection. J Chromatogr 1985;329:99-105.

16. Hayman M, Kam PCA. Capsaicin: a review of its pharmacology and clinical applications. Curr Anaesth Crit Care 2008;19:338-43.

17. Govindarajan VS, Sathyanarayana MN. Capsicumproduction, technology, chemistry, and quality. Part V. Impact on physiology, pharmacology, nutrition, and metabolism; structure, pungency, pain, and desensitization sequences. Crit Rev Food Sci Nutr 1991;29:435-73.

18. Tyagi P, Chancellor MB, Li Z, Groat WC, Yoshimura N, Fraser MO, et al. Urodynamic and immunohistochemical evaluation of intravesical capsaicin delivery using thermosensitive hydrogel and liposomes. J Urol 2004;171:483-9.

19. Zi P, Yang X, Kuanga H, Yanga Y, Yub L. Effect of HP $\beta C D$ on solubility and transdermal delivery of capsaicin through rat skin. Int J Pharm 2008;358:151-8.

20. Webster LR, Malan TP, Tuchman MM, Mollen MD, Tobias JK, Vanhove GF. A multicenter, randomized, doubleblind, controlled dose finding study of NGX-4010, a highconcentration capsaicin patch, for the treatment of postherpetic neuralgia. J Pain 2010;11:972-82.

21. Yamauchi TT, Saitoh T, Shirai K, Fujiki K, Tsubokawa N. Immobilization of capsaicin onto silica nanoparticle surface and stimulus properties of the capsaicin immobilized silica. J Polym Sci 2010;48:1800-5.

22. Semalty A, Semalty M, Rawat BS, Singh D, Rawat MSM. Pharmacosomes: the lipid based novel drug delivery system. Expert Opin Drug Deliv 2009;6:599-612.

23. Virtanen JA, Cheng KH, Somerharju P. Phospholipid composition of the mammalian red cell membrane can be rationalized by a superlattice model. Proc Natl Acad Sci USA 1998;95:4964-9.

24. Zhang $\mathrm{K}, \mathrm{Gu} \mathrm{L}$, Chen J, Zhang Y, Jiang Y, Zhao L, et al. Preparation and evaluation of kaempferol-phospholipid complex for pharmacokinetics and bioavailability in SD rats. J Pharm Biomed Anal 2015;114:168-75.
25. Scholfield CR. Composition of soybean lecithin. J Am Oil Chem Soc 1981;58:889-92.

26. Giri TK, Pradhan M, Tripathi DK. Synthesis of graft copolymer of kappa-carrageenan using microwave energy and studies of swelling capacity, flocculation properties, and preliminary acute toxicity. Turk J Chem 2016;40:283-95.

27. Giri TK, Verma D, Badwaik HR. Effect of aluminium chloride concentration on diltiazem hydrochloride release from $\mathrm{pH}$-sentive hydrogel beads composed of hydrolyzed grafted k-carrageenan and sodium alginate. Curr Chem Biol 2017;11:44-9.

28. Giri TK, Dey B, Maity S. Preparation and Characterization of Nanoemulsome Entrapped in Enteric Coated Hydrogel Beads for the Controlled Delivery of Capsaicin to the Colon. Curr Drug Ther 2018;13:98-105.

29. Costa P, Sousa Lobo JM. Modeling and comparison of dissolution profiles. Eur J Pharm Sci 2001;13:123-33.

30. Kidd PM. Bioavailability and activity of phytosome complexes from botanical polyphenols: The silymarin, curcumin, green tea, and grape seed extracts. Altern Med Rev J Clin Ther 2009; 14:226-46.

31. Jin X, Zhang ZH, Sun E, Tan XB, Zhu FX, Jia XB. A novel drug-phospholipid complex loaded micelle for baohuoside I enhanced oral absorption: In vivo and in vivo evaluations. Drug Dev Ind Pharm 2013;39:1421-30.

32. Yanyu X, Yunmei S, Zhipeng C, Qineng P. The preparation of silybin-phospholipid complex and the study on its pharmacokinetics in rats. Int J Pharm 2006;307:77-82.

33. Alexander A, Tripathi DK, Verma T, Swarna Maurya J, Patel S. Mechanism responsible for mucoadhesion of mucoadhesive drug delivery system: a review. Int J Appl Biol Pharm Technol 2011;2:434-45.

34. Peng W, Jiang X, Zhu Y, Omari-Siaw E, Deng W, Yu J, et al. Oral delivery of capsaicin using MPEG-PCL nanoparticles. Acta Pharmacol Sin 2015;36:139-48.

35. Khan J, Alexander A, Ajazuddin, Saraf S, Saraf S. Luteolinphospholipid complex: preparation, characterization and biological evaluation. J Pharm Pharmacol 2014;66:1451-62.

36. Li L, Liu Y, Xue Y, Zhu J, Wang X, Dong Y. Preparation of a ferulic acid-phospholipid complex to improve solubility, dissolution, and B16F10 cellular melanogenesis inhibition activity. Chem Cent J 2017;11:1-8.

37. Zhang J, Tang Q, Xu X, Li N. Development and evaluation of a novel phytosome-loaded chitosan microsphere system for curcumin delivery. Int J Pharm 2013;448:168-74.

38. Almeida MA, Nadal JM, Grassiolli S, Paludo KS, Zawadzki SF, Cruz L, et al. Enhanced gastric tolerability and improved anti-obesity effect of capsaicinoids-loaded PCL microparticles. Mater Sci Eng C Mater Biol Appl 2014;40:345-56.

39. Ruan J, Liu J, Zhu D, Gong T, Yang F, Hao X, et al. Preparation and evaluation of self-nanoemulsified drug delivery systems (SNEDDSs) of matrine based on drug-phospholipid complex technique. Int J Pharm 2010;386:282-90.

40. Semalty A, Semalty M, Singh D, Rawat MSM. Preparation and characterization of phospholipid complexes of naringenin for effective drug delivery. J Incl Phenom Macrocycl Chem 2010;67:253-60.

41. Galasso V, Asaro F, Berti F, Pergolese B, Kovac B, Pichierri F. On the molecular and electronic structure of matrine-type alkaloids. Chem Phys 2006;330:457-68.

42. Lasonder E, Weringa WD. An NMR and DSC study of 
the interaction of phospholipid vesicles with some antiinflammatory agents. J Colloid Interface Sci 1990;2:469-78.

43. Semalty A. Cyclodextrin and phospholipid complexation in solubility and dissolution enhancement: a critical and metaanalysis. J Expert Opin Drug Deliv 2016;11:1255-72.

44. Telange DR, Patil AT, Pethe AM, Fegade H, Anand S, Dave VS. Formulation and characterization of an apigeninphospholipid phytosome (APLC) for improved solubility, in vivo bioavailability, and antioxidant potential. Eur J Pharm Sci 2017;108:36-49.

45. Cai X, Luan Y, Jiang Y, Song A, Shao W, Li Z, et al. Huperzine A phospholipid complex-loaded biodegradable thermosensitive polymer gel for controlled drug release. Int J Pharm 2012;433:102-11.

46. Semalty A, Semalty M, Singh D, Rawat MSM. Development and physicochemical evaluation of pharmacosomes of diclofenac. Acta Pharma 2009;59:335-44.

47. Singh D, Rawat MSM, Semalty A, Semalty M. Chrysophanolphospholipid complex. J Therm Anal Calorim 2012;111:206977.

48. Xia HJ, Zhang ZH, Jin X, Hu Q, Chen XY, Jia XB. A novel drug phospholipid complex enriched with micelles: preparation and evaluation in vitro and in vivo. Int $\mathrm{J}$ Nanomedicine 2013;8:545-54.

49. Perrut M, Jung J, Leboeuf F. Enhancement of dissolution rate of poorly-soluble active ingredients by supercritical fluid processes: part I: micronization of neat particles. Int J Pharm 2005;288:3-10.

50. Jarmer DJ, Lengsfeld CS, Anseth KS, Randolph TW. Supercritical fluid crystallization of griseofulvin: Crystal habit modification with a selective growth inhibitor. J Pharm Sci 2005;94:2688-702. 